\title{
Retraction Note: Simulation of Crack Growth Using Cohesive Crack Method
}

\author{
Retraction note to: KSCE Journal of Civil Engineering (2010) 14(5):765-772 \\ DOI 10.1007/s12205-010-1050-3
}

The editors of the KSCE Journal of Civil Engineering hereby retract the article "Simulation of Crack Growth Using Cohesive Crack Method" by Billy Chong, published in Volume 14, No. 5, September 2010, pp. 765-772. It has come to the attention of the editors that substantial sections of the text of this article have been taken verbatim from the article "Analysis of Cohesive Crack Growth by the Element-Free Galerkin Method" by P. Soparat and P. Nanakorn, published in the Journal of Mechanics,
Volume 24, No. 1, March 2008, without appropriate reference. An internal investigation has raised sufficient concerns about ethical misconduct. As such, the editors retract this article from the literature in accordance with the guidelines and editorial practices of Publication Ethics. The editors apologize to readers that this was not detected during the submission and review process.

\section{References}

[1] Chong, B. (2010). "Simulation of crack growth using cohesive crack method." KSCE Journal of Civil Engineering, KSCE, Vol. 14, No. 5, pp. 765-772, DOI: 10.1007/s12205-010-1050-3.

[2] Soparat, P. and Nanakorn, P. (2008). "Analysis of cohesive crack growth by the element-Free galerkin method." Journal of Mechanics, Vol. 24, No. 1, pp. 45-54. 